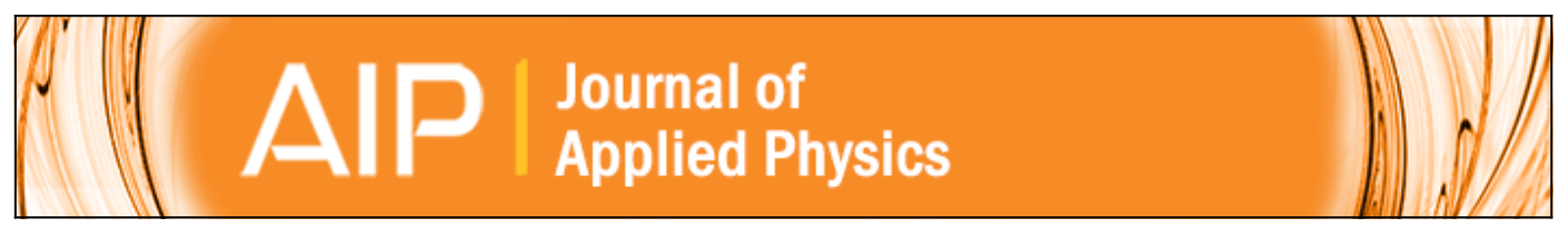

\title{
Thermoelectric transport properties of diamond-like Cu1-xFe1+xS2 tetrahedral compounds
}

Yulong Li, Tiansong Zhang, Yuting Qin, Tristan Day, G. Jeffrey Snyder, Xun Shi, and Lidong Chen

Citation: Journal of Applied Physics 116, 203705 (2014); doi: 10.1063/1.4902849

View online: http://dx.doi.org/10.1063/1.4902849

View Table of Contents: http://scitation.aip.org/content/aip/journal/jap/116/20?ver=pdfcov

Published by the AIP Publishing

\section{Articles you may be interested in}

Enhanced thermoelectric performance in Cd doped CulnTe2 compounds

J. Appl. Phys. 115, 163705 (2014); 10.1063/1.4872250

Composition dependence of thermoelectric properties in polycrystalline type-I Ba8Ga x Si46-x (nominal x=14-18) AIP Conf. Proc. 1449, 259 (2012); 10.1063/1.4731546

Effect of chemical doping on the thermoelectric properties of FeGa3

J. Appl. Phys. 109, 103712 (2011); 10.1063/1.3585843

High temperature thermoelectric properties of double-filled In $x$ Yb y Co $4 \mathrm{Sb} 12$ skutterudites J. Appl. Phys. 105, 084907 (2009); 10.1063/1.3116151

High temperature thermoelectric transport properties of $\mathrm{p}$-type $\mathrm{Ba} 8 \mathrm{Ga} 16 \mathrm{Al} \times \mathrm{Ge} 30-\mathrm{x}$ type-I clathrates with high performance

J. Appl. Phys. 103, 073503 (2008); 10.1063/1.2902504

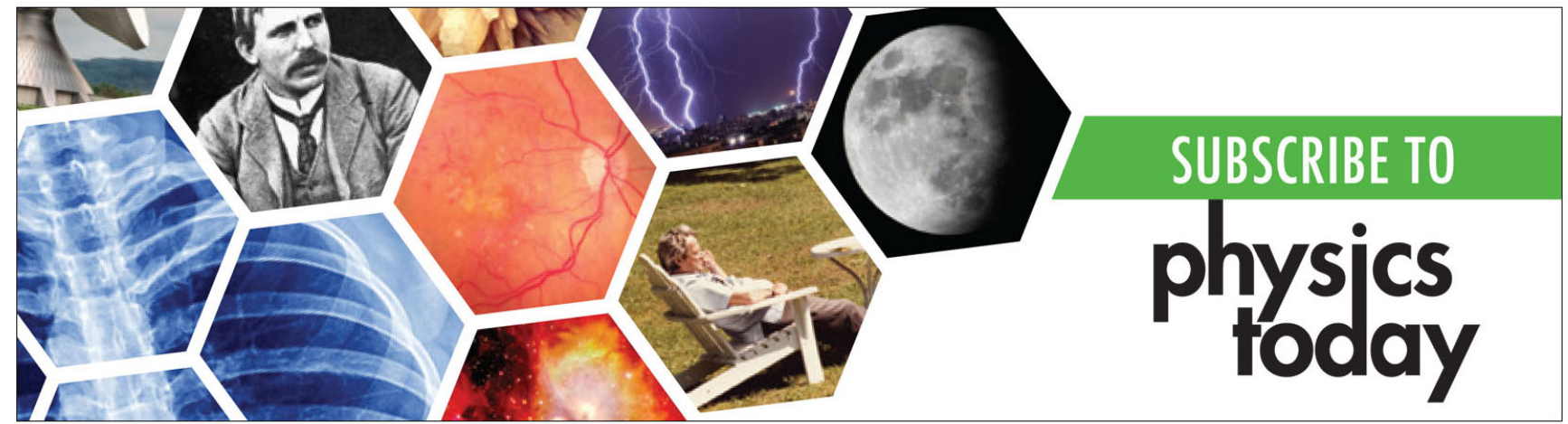




\title{
Thermoelectric transport properties of diamond-like $\mathrm{Cu}_{1-\mathrm{x}} \mathrm{Fe}_{1+\mathrm{x}} \mathrm{S}_{2}$ tetrahedral compounds
}

\author{
Yulong Li, ${ }^{1,2,3}$ Tiansong Zhang, ${ }_{1,2}^{1,2}$ Yuting Qin,,${ }^{1,2,3}$ Tristan Day, ${ }^{4}$ G. Jeffrey Snyder, ${ }^{4}$ \\ Xun Shi, ${ }^{1,2, a)}$ and Lidong Chen ${ }^{1,2, a)}$ \\ ${ }^{1}$ State Key Laboratory of High Performance Ceramics and Superfine Microstructure, Shanghai Institute \\ of Ceramics, Chinese Academy of Sciences, Shanghai 200050, China \\ ${ }^{2}$ CAS Key Laboratory of Materials for Energy Conversion, Shanghai Institute of Ceramics, \\ Chinese Academy of Sciences, Shanghai 200050, China \\ ${ }^{3}$ University of Chinese Academy of Sciences, Beijing 100049, China \\ ${ }^{4}$ Department of Materials Science, California Institute of Technology, Pasadena, California 91125, USA
}

(Received 4 September 2014; accepted 15 November 2014; published online 26 November 2014)

\begin{abstract}
Polycrystalline samples with the composition of $\mathrm{Cu}_{1-x} \mathrm{Fe}_{1+\mathrm{x}} \mathrm{S}_{2}(\mathrm{x}=0,0.01,0.03,0.05,0.1)$ were synthesized by a melting-annealing-sintering process. X-ray powder diffraction reveals all the samples are phase pure. The backscattered electron image and X-ray map indicate that all elements are distributed homogeneously in the matrix. The measurements of Hall coefficient, electrical conductivity, and Seebeck coefficient show that $\mathrm{Fe}$ is an effective n-type dopant in $\mathrm{CuFeS}_{2}$. The electron carrier concentration of $\mathrm{Cu}_{1-x} \mathrm{Fe}_{1+x} \mathrm{~S}_{2}$ is tuned within a wide range leading to optimized power factors. The lattice phonons are also strongly scattered by the substitution of $\mathrm{Fe}$ for $\mathrm{Cu}$, leading to reduced thermal conductivity. We use Debye approximation to model the low temperature lattice thermal conductivity. It is found that the large strain field fluctuation introduced by the disordered Fe ions generates extra strong phonon scatterings for lowered lattice thermal conductivity. (C) 2014 AIP Publishing LLC. [http://dx.doi.org/10.1063/1.4902849]
\end{abstract}

\section{INTRODUCTION}

Thermoelectric materials have attracted extensive attention due to the potential applications in heat pumping and power generation. ${ }^{1,2}$ The performance of thermoelectric materials is determined by the dimensionless thermoelectric figure of merit $z T=\alpha^{2} \sigma T / \kappa$, where $\alpha$ is the Seebeck coefficient, $\sigma$ is the electrical conductivity, $T$ is the absolute temperature, and $\kappa$ is the thermal conductivity. The strategy of maximizing $z T$ is to obtain large power factor $\left(\alpha^{2} \sigma\right)$ as well as low thermal conductivity. ${ }^{3}$ Advanced thermoelectric materials including $\mathrm{Bi}_{2} \mathrm{Te}_{3}{ }^{4}{ }^{4} \mathrm{PbTe},{ }^{5,6}$ skutterudites, ${ }^{7,8}$ clathrates, ${ }^{9} \mathrm{Cu}_{2} \mathrm{X}(\mathrm{X}=\mathrm{S}$, $\mathrm{Se}),{ }^{10,11}$ etc., have been continually discovered and investigated to enhance the $z T s$. In particular, in order to meet industry requirements, the high performance earth-abundant, low-cost, nontoxic, and environmentally benign thermoelectric materials have drawn lots of attention recently. ${ }^{2,11,12}$

A family of compounds with diamond-like structure, such as $\mathrm{Cu}_{2} \mathrm{ZnSn}_{1-\mathrm{x}} \mathrm{In}_{\mathrm{x}} \mathrm{Se}_{4}, \mathrm{Cu}_{2} \mathrm{Sn}_{1-\mathrm{x}} \mathrm{In}_{\mathrm{x}} \mathrm{Se}_{3}, \mathrm{CuInTe}_{2}$, and $\mathrm{CuGaTe}_{2},{ }^{13-16}$ has emerged as promising thermoelectric materials in the past few years. The diamond-like compounds derive from binary cubic zinc-blende compounds by using various elements substituted at $\mathrm{Zn}$ sites. Due to the different physical and chemical properties of the substituted elements at $\mathrm{Zn}$ sites, the crystal lattice is distorted from the perfectly cubic diamond lattice to lower the lattice thermal conductivity. By combining the optimization of electrical properties, the $z T s$ up to 1.2-1.4 are reported in current diamond-like compounds. These high $z T$ values are mainly realized in the tetrahedral compounds such as $\mathrm{CuInTe}_{2}$ and $\mathrm{CuGaTe}_{2}$. By using

${ }^{a)}$ Electronic addresses: xshi@mail.sic.ac.cn and cld@mail.sic.ac.cn first principle calculations, Zhang et al. did a systemic study on the tetrahedral diamond-like compounds. ${ }^{17}$ An effective unity- $\eta$ rule is proposed to explain the current high $z T s$ in $\mathrm{CuInTe}_{2}, \mathrm{CuGaTe}_{2}$, and $\mathrm{Cu}_{2} \mathrm{ZnSn}_{1-\mathrm{x}} \mathrm{In}_{\mathrm{x}} \mathrm{Se}_{4}$, where $\eta=c / 2 a$, and $c$ and $a$ are lattice parameters. When $\eta$ is around 1 , the crystal field splitting energy reaches the minimum state, leading to a cubic-like highly degenerate electronic band-edge state for large power factors and high $z T$ values. This unity- $\eta$ rule can also be used to predict and search for novel tetrahedral non-cubic thermoelectric materials, in particular for those diamond-like materials with similar crystal structures.

Chalcopyrite ore $\mathrm{CuFeS}_{2}$ composed of earth-abundant, non-toxic, and inexpensive elements $\mathrm{Cu}, \mathrm{Fe}$, and $\mathrm{S}$, is also a diamond-like compound with tetrahedral structure. The experimental lattice parameters are $10.42 \AA$ for $c$ and $5.289 \AA$ for $a$. The calculated $\eta$ value in $\mathrm{CuFeS}_{2}$ is 0.985 , which shows a larger deviation than those in $\mathrm{CuInTe}_{2}$ and $\mathrm{CuGaTe}_{2}$, but still quite close to 1 . This suggests that $\mathrm{CuFeS}_{2}$ might possess good electrical properties as well as thermoelectric figure of merit since the lattice thermal conductivity is usually low in these diamond-like compounds. $\mathrm{CuFeS}_{2}$ is a narrow band gap semiconductor with a gap $\left(E_{g}\right)$ of $0.53 \mathrm{eV}$ by optical absorption measurement or $0.3 \mathrm{eV}$ by the calculation using spin-polarized self-consistent charge discrete-variational $X \alpha$ method. ${ }^{18,19}$ A Seebeck coefficient $-480 \mu \mathrm{V} / \mathrm{K}$ and a carrier concentration $10^{19} \mathrm{~cm}^{-3}$ at room temperature are reported. ${ }^{20,21}$ These data confirmed that $\mathrm{CuFeS}_{2}$ is a good semiconductor within the range of heavily doped materials, and these are particularly suitable for advanced thermoelectric materials.

$\mathrm{CuFeS}_{2}$ with stoichiometric chemical composition is an intrinsic semiconductor with poor power factors. The carrier 
concentration must be tuned to the optimum value for thermoelectric performance. Li et al. used $\mathrm{S}$ deficiency to increase carrier concentrations in $\mathrm{CuFeS}_{2-\mathrm{x}}$ to approach the optimum value, leading to enhanced power factors. ${ }^{22} \mathrm{~A}$ decreased thermal conductivity is also obtained by the enhanced phonon-interface scattering. A maximum $z T$ value of 0.21 was obtained at $573 \mathrm{~K}$ for $\mathrm{CuFeS}_{1.80}$. Naohito Tsujii and Takao Mori studied mainly the low temperature thermoelectric properties of carrier-doped $\mathrm{Cu}_{1-x} \mathrm{Fe}_{1+\mathrm{x}} \mathrm{S}_{2}$. They assumed that the strong magnetic moment can affect charge carriers based on the early references, resulting in increased electron effective mass and subsequently high power factors. ${ }^{23,24}$ However, the carrier-magnetic moment interactions are expected to be weak or to disappear at high temperatures. Thus the electrical transport at high temperatures in the $\mathrm{CuFeS}_{2}$ compound should be dominated by the material's band structure and carrier concentration. In addition, the lattice defects by the arrangement of $\mathrm{Cu}$ and $\mathrm{Fe}$ atoms in the material could also affect the heat conduction, in particular for the material $\mathrm{Cu}_{1-x} \mathrm{Fe}_{1+\mathrm{x}} \mathrm{S}_{2}$ with $\mathrm{Cu}$ and $\mathrm{Fe}$ contents significantly shifted from the stoichiometric ratio. Both of these two factors will obviously affect the thermoelectric properties and should be clarified to fully understand the chalcopyrite ore compound $\mathrm{CuFeS}_{2}$.

In this work, we present a systematic study of the thermoelectric properties of chalcopyrite $\mathrm{Cu}_{1-\mathrm{x}} \mathrm{Fe}_{1+\mathrm{x}} \mathrm{S}_{2}$ from liquid helium temperature to $700 \mathrm{~K}$. Significantly improved electrical transport and lowered thermal conductivity are observed to show enhanced $z T$ values. The effect of the excessive $\mathrm{Fe}$ substituted at $\mathrm{Cu}$ sites in $\mathrm{CuFeS}_{2}$ on the electrical and thermal transport and their physical mechanisms are discussed.

\section{EXPERIMENT}

Polycrystalline $\mathrm{Cu}_{1-\mathrm{x}} \mathrm{Fe}_{1+\mathrm{x}} \mathrm{S}_{2}(\mathrm{x}=0,0.01,0.03,0.05$, and 0.1 ) samples were synthesized by a melting-annealingsintering process. High purity elements $\mathrm{Cu}$ (shot, 99.999\%), Fe (pieces, 99.99\%), and S (pieces, 99.999\%) in stoichiometric proportions were sealed in evacuated quartz tubes. The quartz tubes were heated slowly up to $1400 \mathrm{~K}$ and stayed at this temperature for $36 \mathrm{~h}$, and then naturally cooled to room temperature. The obtained ingots were ground into fine powders and cold pressed into pellets. The pellets were resealed in quartz tubes and annealed at $800-900 \mathrm{~K}$ for 7 days. The resulted materials were reground into powders and then sintered by spark plasma sintering at $800-820 \mathrm{~K}$ under a pressure of $60 \mathrm{MPa}$ to obtain densified bulk samples.

The phase, morphology, and chemical compositions of the samples were characterized by powder X-ray diffraction (XRD) analysis (Rigaku, Rint2000, Cu $K \alpha$ ), scanning electron microscope (SEM), and energy dispersive spectrometer (EDS), respectively.

The measurements of Hall coefficient $R_{H}$, electrical conductivity $\sigma$, thermal conductivity $\kappa$, and Seebeck coefficient $\alpha$ at low temperature $(2-300 \mathrm{~K})$ were carried out in a Quantum Design Physics Property Measurement System. The high temperature measurements of electrical conductivity and Seebeck coefficient were performed in the ZEM-3
(ULVAC-RIKO) from 300 to $700 \mathrm{~K}$. The high temperature thermal diffusivity $(\lambda)$ was measured using the laser flash method in flowing argon atmosphere (NETZSCH LFA 457). The thermal conductivity was calculated from $\kappa=\lambda C_{p} \rho$, where the Dulong-Petit value of $0.518 \mathrm{~J} / \mathrm{gK}$ was used for the specific heat capacity $\left(C_{p}\right)$ and the density $(\rho)$ was measured using Archimedes method. The velocity of sound was measured by using a Panametrics NDT 5800 pulser/receiver and $5 \mathrm{MHz}$ and $25 \mathrm{MHz}$ shear and longitudinal transducers from Ultran.

\section{RESULTS AND DISCUSSION}

\section{A. Structural and compositional characterizations}

Figure 1 shows the powder X-ray diffraction patterns for $\mathrm{Cu}_{1-\mathrm{X}} \mathrm{Fe}_{1+\mathrm{X}} \mathrm{S}_{2}$ samples. All diffraction peaks are consistent with the standard pattern of tetragonal $\mathrm{CuFeS}_{2}$ (JCPDS No. 65-1573) with the space group of I42d. Impurity phases are not observed in the X-ray diffraction patterns even for the sample with the largest $\mathrm{x}$ value $(\mathrm{x}=0.1)$. In order to check the element distribution of this sample in microscopic prospective, the backscattered electron (BSE) image of the polished surface and $\mathrm{x}$-ray map by EDS for sample $\mathrm{Cu}_{0.9} \mathrm{Fe}_{1.1} \mathrm{~S}_{2}$ are shown in Figure 2. Element $\mathrm{Cu}, \mathrm{Fe}$, and $\mathrm{S}$ are all homogeneously distributed in the samples and no obvious large impurity phases are detected. These data strongly suggest that the $\mathrm{Fe}$ atoms can substitute at $\mathrm{Cu}$ sites with content up to at least $10 \%$.

The atomic ratio of $\mathrm{Fe} / \mathrm{Cu}$ by EDS measurements is shown in Table I. Due to the measurement uncertainty or errors, the atomic ratio of $\mathrm{Fe} / \mathrm{Cu}$ is not ideally equal to the initial atomic ratios in all samples, even for sample $\mathrm{CuFeS}_{2}$. However, the atomic ratio of $\mathrm{Fe} / \mathrm{Cu}$ increases monotonically with increasing $\mathrm{Fe}$ content, which shows the same trend as the designed staring compositions. Therefore, by combining Figs. 1 and 2, and Table I, we conclude that the $\mathrm{Fe} / \mathrm{Cu}$ atomic ratios in $\mathrm{CuFeS}_{2}$ can be tuned in a certain large composition range such as the composition of $\mathrm{Cu}_{0.9} \mathrm{Fe}_{1.1} \mathrm{~S}_{2}$.

\section{B. High-temperature thermoelectric properties}

Figure 3 shows the temperature dependence of electrical conductivity $(\sigma)$ and Seebeck coefficient $(\alpha)$ for all the samples. As $\mathrm{Fe}$ doping on the $\mathrm{Cu}$ site, the value of electrical

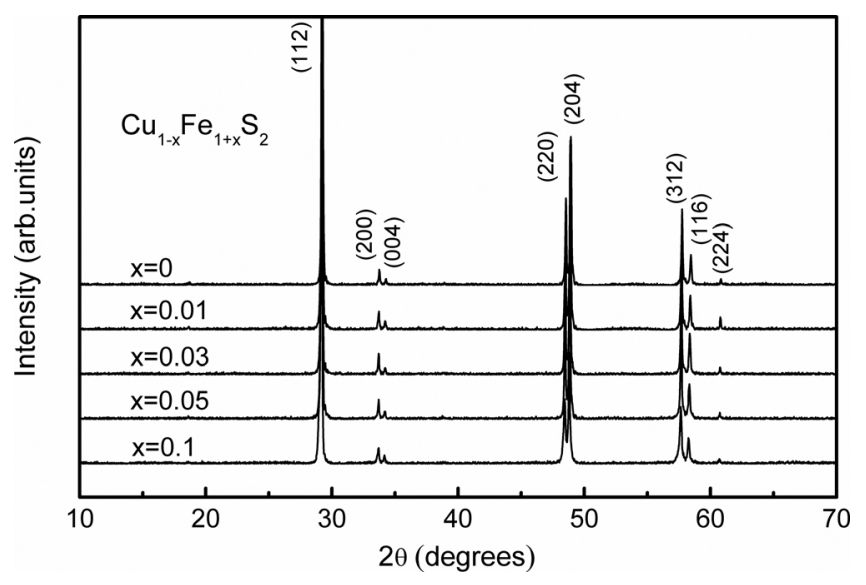

FIG. 1. XRD patterns for $\mathrm{Cu}_{1-\mathrm{x}} \mathrm{Fe}_{1+\mathrm{x}} \mathrm{S}_{2}$. 


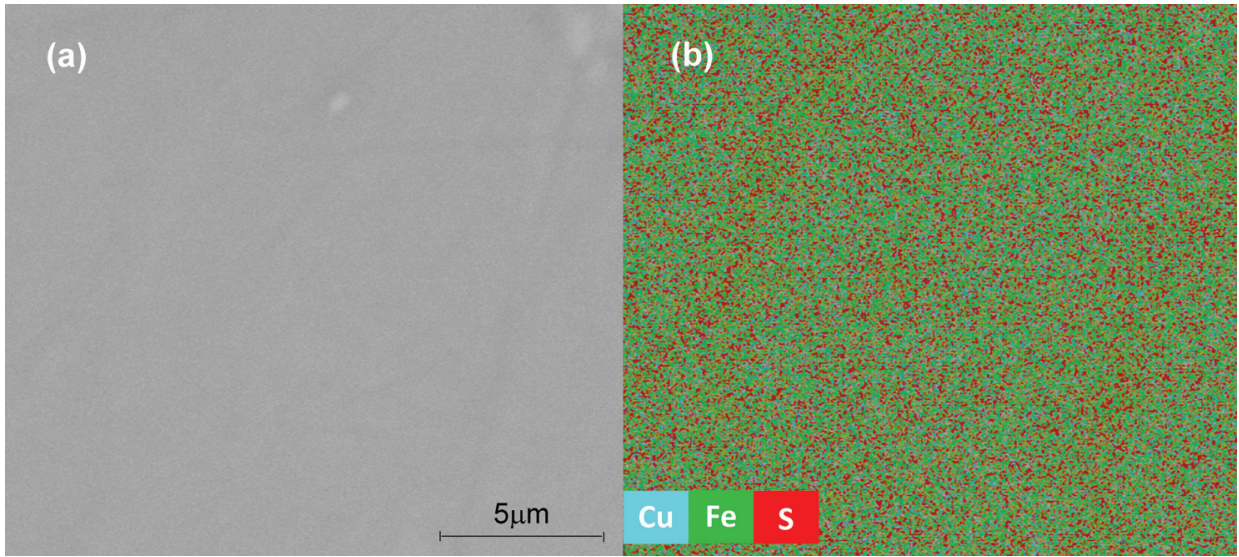

FIG. 2. (a) BSE image of the polished surface and (b) x-ray map by EDS for sample $\mathrm{Cu}_{0.9} \mathrm{Fe}_{1.1} \mathrm{~S}_{2}$.

TABLE I. Nominal compositions, atom ratio of Fe/Cu based on the EDS measurement, volume of unit cell $V$, band gap $E_{g}$, and room temperature lattice thermal conductivity $\kappa_{L}$, electrical conductivity $\sigma$, Seebeck coefficient $\alpha$, Hall carrier concentration $n$, Hall mobility $\mu_{H}$ in $\mathrm{Cu}_{1-\mathrm{x}} \mathrm{Fe}_{1+\mathrm{x}} \mathrm{S}_{2}$.

\begin{tabular}{|c|c|c|c|c|c|c|c|c|}
\hline $\begin{array}{l}\text { Nominal } \\
\text { Composition }\end{array}$ & $\begin{array}{c}\mathrm{Fe} / \mathrm{Cu} \\
\text { (atomic ratio) }\end{array}$ & $\begin{array}{c}V\left(a^{2} c\right) \\
\left(\AA^{3}\right)\end{array}$ & $\begin{array}{c}\kappa_{L} \\
(\mathrm{~W} / \mathrm{mK})\end{array}$ & $\begin{array}{c}\sigma \\
\left(10^{4} \Omega^{-1} \mathrm{~m}^{-1}\right)\end{array}$ & $\begin{array}{c}\alpha \\
(\mu \mathrm{V} / \mathrm{K})\end{array}$ & $\begin{array}{c}n \\
\left(10^{20} \mathrm{~cm}^{-3}\right)\end{array}$ & $\begin{array}{c}\mu_{H} \\
\left(\mathrm{~cm}^{2} / \mathrm{Vs}\right)\end{array}$ & $\begin{array}{c}E_{g} \\
(\mathrm{eV})\end{array}$ \\
\hline $\mathrm{CuFeS}_{2}$ & 1.005 & 291.75 & 5.9 & 0.25 & -370 & 0.34 & 3.0 & 0.34 \\
\hline $\mathrm{Cu}_{0.99} \mathrm{Fe}_{1.01} \mathrm{~S}_{2}$ & 1.020 & 292.04 & 5.7 & 0.74 & -307 & 0.75 & 5.1 & 0.36 \\
\hline $\mathrm{Cu}_{0.97} \mathrm{Fe}_{1.03} \mathrm{~S}_{2}$ & 1.102 & 292.30 & 4.2 & 1.45 & -224 & 2.11 & 3.6 & 0.32 \\
\hline $\mathrm{Cu}_{0.95} \mathrm{Fe}_{1.05} \mathrm{~S}_{2}$ & 1.132 & 292.68 & 3.8 & 1.95 & -189 & 3.42 & 3.3 & 0.29 \\
\hline $\mathrm{Cu}_{0.9} \mathrm{Fe}_{1.1} \mathrm{~S}_{2}$ & 1.175 & 292.74 & 3.2 & 2.11 & -139 & 7.02 & 1.7 & 0.19 \\
\hline
\end{tabular}

conductivity increases with increasing $\mathrm{Fe}$ doping content while the absolute value of Seebeck coefficient decreases. The detailed mechanisms will be discussed below. All samples exhibit negative Seebeck coefficients in the whole measured temperature range, indicating n-type materials with electrons as the charge carriers. When temperature is increasing, the absolute values of Seebeck coefficient increase first and then decline due to thermal excitation of carriers. This indicates these samples could be treated as intrinsic semiconductors at high temperatures. For an intrinsic semiconductor, both electrons and holes contribute to the electrical transport and they make opposite contributions to the total Seebeck coefficient. Thus reduced Seebeck coefficients are expected, which can be described by ${ }^{25}$

$$
\alpha=\frac{\alpha_{e} \sigma_{e}+\alpha_{h} \sigma_{h}}{\sigma_{e}+\sigma_{h}},
$$

where the subscript symbols $e$ and $h$ represent electron and hole, respectively.
For sample $\mathrm{CuFeS}_{2}$, the intrinsically thermal excitation occurs at $400 \mathrm{~K}$, which indicates a relatively small band gap $\left(E_{\mathrm{g}}\right)$. The $E_{\mathrm{g}}$ can be estimated by ${ }^{25}$

$$
E_{g}=2 e \alpha_{\max } T_{\max }
$$

where $e$ is the electron charge, $\alpha_{\max }$ is the maximum value of Seebeck coefficient, and $T_{\max }$ is the temperature at which the maximum thermopower occurs. The estimated $E_{\mathrm{g}}$ for $\mathrm{CuFeS}_{2}$ is about $0.34 \mathrm{eV}$, in agreement with the calculated $0.3 \mathrm{eV}$ in Ref. 19, but smaller than the value by optical absorption measurement. ${ }^{18}$ With increasing Fe doping content, the $T_{\max }$ moves towards high temperature gradually except for the sample with $x=0.1$.

Like other high thermoelectric performance diamondlike compounds, $\mathrm{Cu}_{1-\mathrm{x}} \mathrm{Fe}_{1+\mathrm{x}} \mathrm{S}_{2}$ also shows relatively low thermal conductivity due to the highly distorted crystal structures, especially at high temperature, as shown in Figure 4. The thermal conductivity is reduced dramatically with increasing temperatures. This is similar to those in almost all
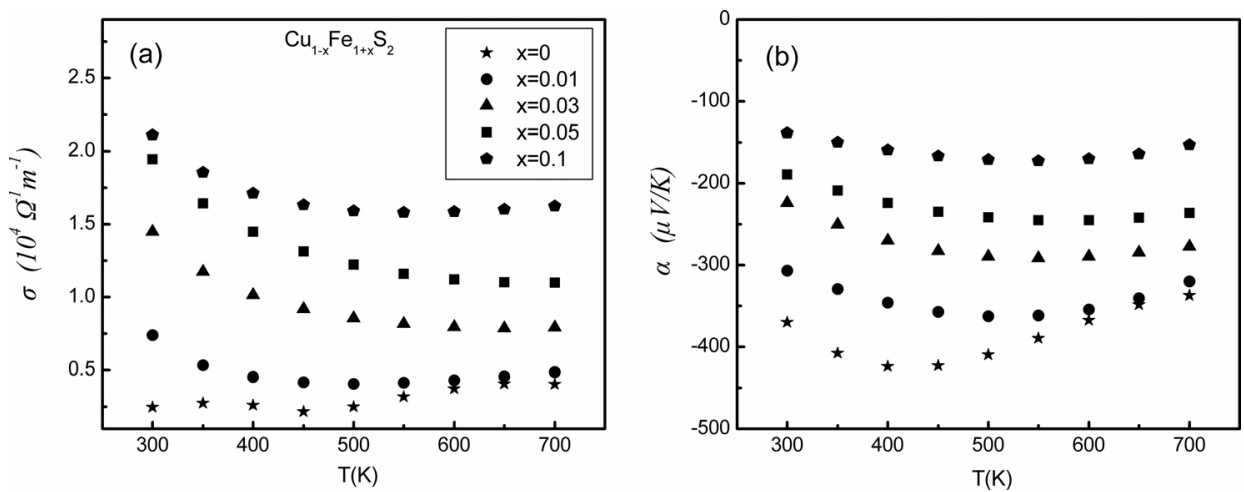

FIG. 3. Temperature dependence of (a) electrical conductivity $\sigma$ and (b) Seebeck coefficient $\alpha$ for $\mathrm{Cu}_{1-\mathrm{x}} \mathrm{Fe}_{1+\mathrm{x}} \mathrm{S}_{2}$ samples $(300 \sim 700 \mathrm{~K})$. 
diamond-like compounds due to strong phonon Umklapp scattering at high temperatures. In addition, the thermal conductivity is decreases significantly with increasing $\mathrm{Fe} / \mathrm{Cu}$ atomic ratios in the entire temperature range. This could be due to the extra lattice defects between the $\mathrm{Fe}$ and $\mathrm{Cu}$ atoms and the details will be discussed in Sec. III D. The minimum value of thermal conductivity for $\mathrm{Cu}_{0.9} \mathrm{Fe}_{1.1} \mathrm{~S}_{2}$ is about $1 \mathrm{~W} /$ $\mathrm{m} \cdot \mathrm{K}$ at $700 \mathrm{~K}$, a quite low value in the diamond-like compounds. Fig. 4 also lists the thermal conductivity of other typical diamond-like compounds. $\mathrm{CuFeS}_{2}$-based materials show lower thermal conductivity than those in other ternary compounds such as $\mathrm{CuInTe}_{2}$ and $\mathrm{CuGaTe}_{2}$. Even compared with the thermal conductivity of quaternary compounds, $\mathrm{CuFeS}_{2}$-based materials with large $\mathrm{Fe} / \mathrm{Cu}$ atomic ratios still show lower values at high temperatures. ${ }^{13-16}$

Figure 5 shows the temperature dependence of the figure of merit $z T\left(=\alpha^{2} \sigma T / \kappa\right)$ from 300 to $700 \mathrm{~K}$ for $\mathrm{Cu}_{1-\mathrm{x}} \mathrm{Fe}_{1+\mathrm{x}} \mathrm{S}_{2}$. The $z T$ values of the reported $\mathrm{CuFeS}_{2}$-based compounds from reference 22 and 23 are also plotted in Figure 5 for a comparison. With the increase of temperature, the $z T$ values increase monotonically for all $\mathrm{Cu}_{1-x} \mathrm{Fe}_{1+x} \mathrm{~S}_{2}$ samples and there is no indication of reaching a maximum value at $700 \mathrm{~K}$. As a result of tuned electrical properties and suppressed thermal conductivity by enlarging the $\mathrm{Fe} / \mathrm{Cu}$ atomic ratios, the $z T$ value is much improved, more than $50 \%$ enhancement in sample $\mathrm{Cu}_{0.97} \mathrm{Fe}_{1.03} \mathrm{~S}_{2}$ and $\mathrm{Cu}_{0.95} \mathrm{Fe}_{1.05} \mathrm{~S}_{2}$ at $700 \mathrm{~K}$ compared with $\mathrm{CuFeS}_{2}$. When the $\mathrm{Fe}$ content is $3 \%$ excess, chalcopyrite $\mathrm{Cu}_{1-\mathrm{x}} \mathrm{Fe}_{1+\mathrm{x}} \mathrm{S}_{2}$ material exhibits a maximum $z T$ value of about 0.33 at $700 \mathrm{~K}$. Further optimization such as other doping with other elements could further reduce the thermal conductivity and enhance electrical properties for the realization of high thermoelectric performance in such a $\mathrm{Cu}-\mathrm{Fe}-\mathrm{S}$ compound with earth-abundant, non-toxic, and inexpensive elements.

\section{Electrical transport properties}

Hall carrier concentration $(n)$ versus $\mathrm{Fe}$ doping content $(x)$ at room temperature for $\mathrm{Cu}_{1-\mathrm{x}} \mathrm{Fe}_{1+\mathrm{x}} \mathrm{S}_{2}$ is plotted in Figure 6. By excessive $\mathrm{Fe}$ substituted at $\mathrm{Cu}$ sites, the electron concentration is significantly increased and a nice linear dependence

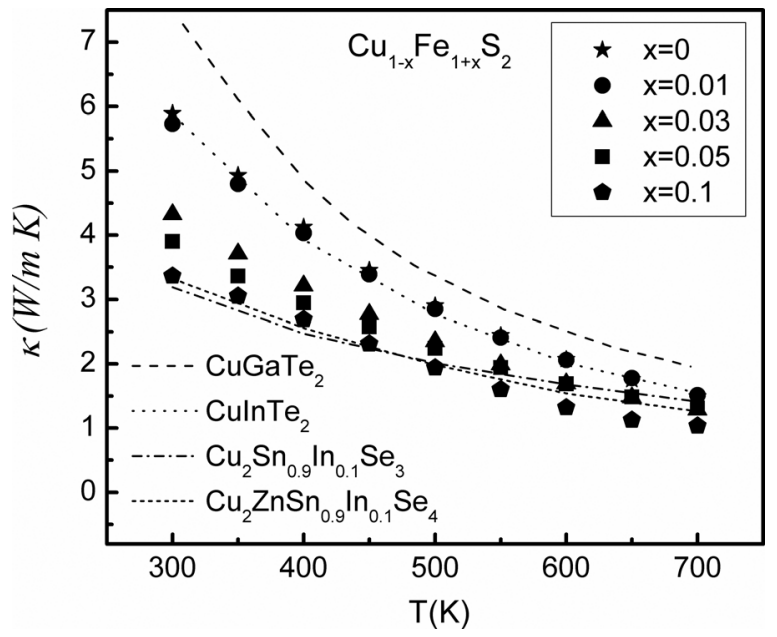

FIG. 4. Temperature dependence of thermal conductivity $(\kappa)$ for $\mathrm{Cu}_{1-x} \mathrm{Fe}_{1+x} \mathrm{~S}_{2}$. The data for other diamond-like compounds from literature $13-16$ are also listed for data comparison. ${ }^{13-16}$

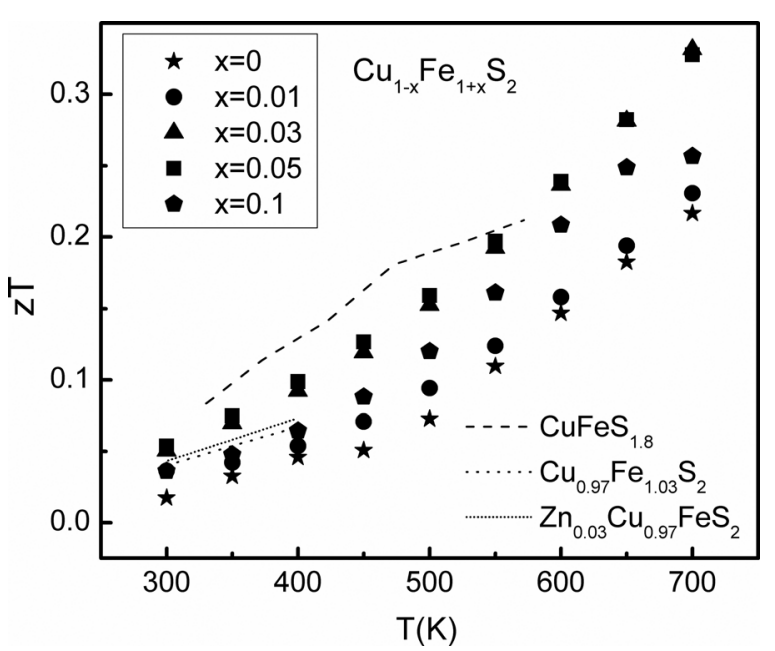

FIG. 5. Temperature dependence of $z T$ for $\mathrm{Cu}_{1-\mathrm{x}} \mathrm{Fe}_{1+\mathrm{x}} \mathrm{S}_{2}(300 \sim 700 \mathrm{~K})$. The data for the reported $\mathrm{CuFeS}_{2}$-based compounds are listed for data comparison. $^{22,23}$

is observed in Fig. 6. The room temperature carrier concentration values are changed in a wide range from $3.4 \times 10^{19} \mathrm{~cm}^{-3}$ to $7 \times 10^{20} \mathrm{~cm}^{-3}$, indicating that $\mathrm{Fe}$ is an effective dopant at the $\mathrm{Cu}$ site. $\mathrm{In} \mathrm{CuFeS}_{2}$, the charge state of $\mathrm{S}$ is usually treated as $2^{-}$. The charge states of $\mathrm{Cu}$ and $\mathrm{Fe}$ are still open questions. The measured and calculated results of the magnetic moment show that the electron states of $\mathrm{CuFeS}_{2}$ are a commixture of $\mathrm{Cu}^{+} \mathrm{Fe}^{3+} \mathrm{S}^{2-}{ }_{2}$ and $\mathrm{Cu}^{2+} \mathrm{Fe}^{2+} \mathrm{S}^{2-}{ }_{2} \cdot{ }^{19,26}$ The enhanced electron concentration by extra $\mathrm{Fe}$ substituted at $\mathrm{Cu}$ sites indicates that $\mathrm{Fe}$ donates more valence electrons than $\mathrm{Cu}$. Therefore, the charge states of $\mathrm{Cu}$ and $\mathrm{Fe}$ in $\mathrm{CuFeS}_{2}$ could be +1 and +3 .

The temperature dependence of Hall mobility $\left(\mu_{H}\right)$ for all the samples is shown in Figure 7. The room temperature Hall mobility of doped samples decreases from 5 to $1.7 \mathrm{~cm}^{2} /$ $\mathrm{V} \cdot \mathrm{s}$ with increasing $\mathrm{Fe}$ content. These values are comparable to the literature data. ${ }^{23}$ For pure $\mathrm{CuFeS}_{2}(\mathrm{x}=0)$, the Hall mobility follows a $T^{3 / 2}$ dependence indicative of ionized impurities dominated carrier scattering. The ionized impurities in $\mathrm{CuFeS}_{2}$ lattice generate a long range Coulomb potential field to scatter electrons strongly, leading to the very low mobility

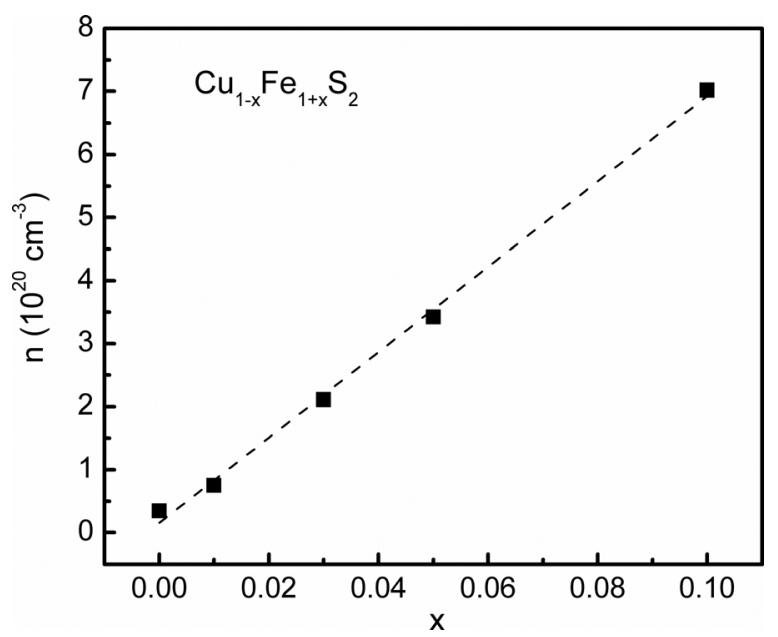

FIG. 6. Hall carrier concentration $(n)$ as a function of doping content $(x)$ at room temperature for $\mathrm{Cu}_{1-x} \mathrm{Fe}_{1+x} \mathrm{~S}_{2}$. The dashed line is a guide to the eyes. 


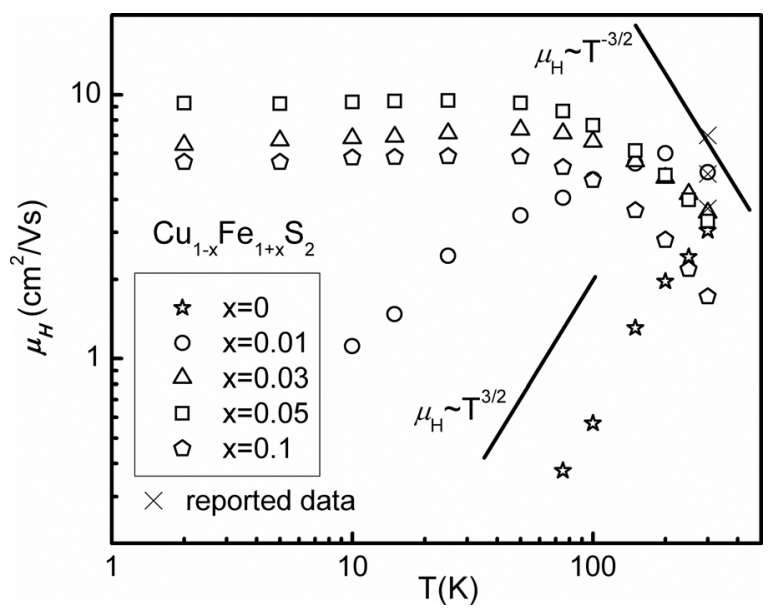

FIG. 7. Temperature dependence of Hall mobility $\left(\mu_{H}\right)$ for $\mathrm{Cu}_{1-x} \mathrm{Fe}_{1+\mathrm{x}} \mathrm{S}_{2}$. The crosses are the reported data from literature 23. The $T^{3 / 2}$ and $T^{-3 / 2}$ relationships are also presented.

of $\mathrm{CuFeS}_{2}$ throughout the whole temperature range investigated. With the increase of Fe content, the temperature dependence of Hall mobility approaches to $\mu_{H} \sim T^{-3 / 2}$ near room temperature in the samples with high carrier concentrations $(x=0.03,0.05,0.1)$, indicating acoustic phonon scatterings start dominating carrier scattering mechanism. ${ }^{27,28} \mathrm{At}$ temperatures below $50 \mathrm{~K}$ the Hall mobility tends towards a constant value, suggestive of neutral impurity scattering. For the $1 \% \mathrm{Fe}$ doped sample $(\mathrm{x}=0.01)$, the temperature dependence of mobility and is more flat at both high and low temperature. This behavior reveals a combination of carrier scattering mechanisms including both acoustic phonons and ionized impurities dominated mechanisms.

With the increase of Fe doping content, the positions of the Fermi level and the variations of the band structure can be inferred roughly from the carrier effective mass. We estimated the electron effective masses of $\mathrm{Cu}_{1-\mathrm{x}} \mathrm{Fe}_{1+\mathrm{x}} \mathrm{S}_{2}$ using the single parabolic band model. In this model, the Seebeck coefficient $\alpha$ and the carrier concentration $n$ are expressed as

$$
\begin{gathered}
\alpha=\frac{k_{B}}{e}\left(\frac{(2+\Lambda) F_{\Lambda+1}(\psi)}{(1+\Lambda) F_{\Lambda}(\psi)}-\psi\right), \\
n=\frac{4 \pi\left(2 m * k_{B} T\right)^{3 / 2}}{h^{3}} F_{1 / 2}(\psi),
\end{gathered}
$$

where $k_{B}$ is the Boltzmann constant, $h$ is the Planck constant, $e$ is elementary charge, $m^{*}$ is the effective mass, $\psi$ is the reduced Fermi level, $F_{j}(\psi)$ is the Fermi integral of order $j$, and $\Lambda$ is a scattering parameter related to the energy dependence of the carrier scattering mechanism. The value of $\Lambda$ is 0 when the acoustic phonon scattering, or 2 when the ionized impurity scattering. ${ }^{29,30}$ The effective mass can be calculated from the experimental values of the Seebeck coefficient and the carrier concentration using Eqs. (3) and (4). $\Lambda$ of 2 is applied to calculate the effective mass of the sample $\mathrm{CuFeS}_{2}$ $(\mathrm{x}=0)$ due to the ionized impurities dominated carrier scattering. For the high carrier concentration samples $(\mathrm{x}=0.03$, $0.05,0.1), \Lambda$ of 0 is used, because dominant carrier scattering mechanism is acoustic phonon scattering. For a comparison,
$\Lambda$ of 1 and 2 are applied to calculate the effective mass of the $1 \%$ Fe doped sample $(x=0.01)$, respectively. Due to the mixed carrier scattering mechanism in $\mathrm{Cu}_{0.99} \mathrm{Fe}_{1.01} \mathrm{~S}_{2}$, the result using $\Lambda=1$ should be closer to the truth. Figure 8 illustrates the calculated effective mass $\left(m^{*}\right)$ as a function of carrier concentration for $\mathrm{Cu}_{1-x} \mathrm{Fe}_{1+\mathrm{x}} \mathrm{S}_{2}$. The effective masses of all the samples are very large, consistent with the calculated heavy effective mass by Naohito Tsujii and Takao Mori, ${ }^{23}$ as shown in Fig. 8, suggestive of relatively large density of state (DOS) near Fermi level. The large density of states could lead to large Seebeck coefficient, but the carrier mobility is also strongly affected to show very low values with the motility data shown in Fig. 7. With the increase of Fe content, the effective mass increases notably, from $1.2 m_{0}$ to $5.6 m_{0}\left(m_{0}\right.$ is the free electron mass), indicating that $\mathrm{Fe}$ substituted on the $\mathrm{Cu}$ site has a strong influence on the band structure around Fermi level. According to the calculated band structure of $\mathrm{CuFeS}_{2}$ by Hamajima et al., the bands around Fermi level are composed mainly of the $3 \mathrm{~d}$ orbital of $\mathrm{Fe}$, which means that the electrical properties of $\mathrm{CuFeS}_{2}$ will be relevant to the $3 \mathrm{~d}$ valence electron of Fe. ${ }^{19}$ Therefore, exactly as the results of effective mass exhibited, the addition of Fe will affect strongly the band structure of $\mathrm{CuFeS}_{2}$.

Figure 9(a) displays the room temperature power factor $\left(\alpha^{2} \sigma\right)$ as a function of carrier concentration $(n)$ for $\mathrm{Cu}_{1-\mathrm{x}} \mathrm{Fe}_{1+\mathrm{x}} \mathrm{S}_{2}$ and the reported data of $\mathrm{CuFeS}_{2}$-based compounds. In our samples, the best power factors are in the range of 7 to $7.3 \times 10^{-4} \mathrm{~W} / \mathrm{mK}^{2}$ for the samples with $\mathrm{x}$ between 0.01 and 0.05 . Although the power factors in our samples are slightly lower than the value from Tsujii et al., all these samples show a clear trend in the relationship between the power factors and carrier concentrations. ${ }^{23}$ The optimum carrier concentration for $\mathrm{CuFeS}_{2}$-based diamondlike compounds is in the range from 1 to $3 \times 10^{20} \mathrm{~cm}^{-3}$. In tetrahedral diamond-like compounds, Zhang et al. reveals the unity- $\eta$ rule to explain and predict the electrical transport

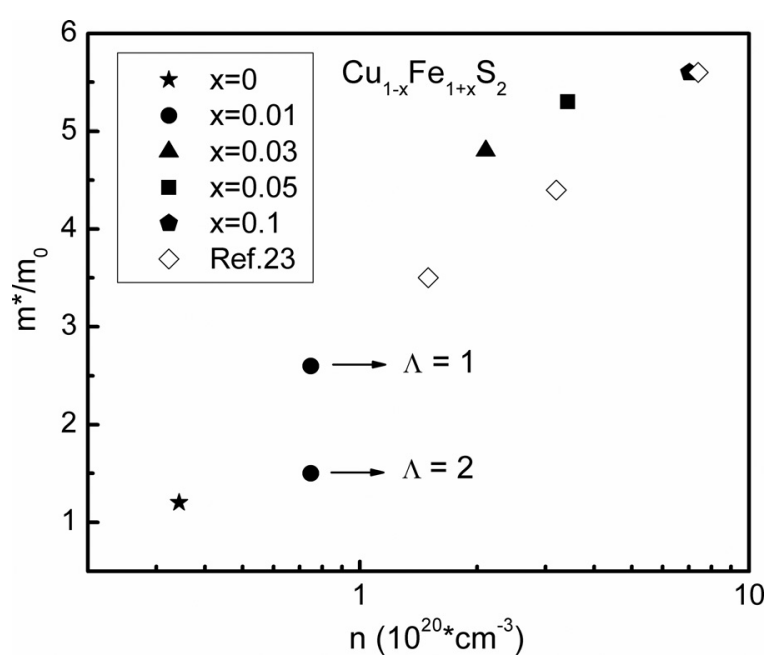

FIG. 8. The electron effective mass $\left(m^{*}\right)$ as a function of carrier concentration $(n)$ for $\mathrm{Cu}_{1-\mathrm{x}} \mathrm{Fe}_{1+\mathrm{x}} \mathrm{S}_{2}$ at room temperature. Due to the different carrier scattering mechanisms in $\mathrm{Cu}_{1-\mathrm{x}} \mathrm{Fe}_{1+\mathrm{x}} \mathrm{S}_{2}$, the $\Lambda$ of 0 is used for the samples with $\mathrm{x}=0.03,0.05,0.1, \Lambda$ of 2 is used for the sample $\mathrm{CuFeS}_{2}(\mathrm{x}=0)$, and $\Lambda$ of 1 and 2 are used for the sample with $x=0.01$ (black points in the Fig. 8). The literature data are plotted for a comparison. ${ }^{23}$ 


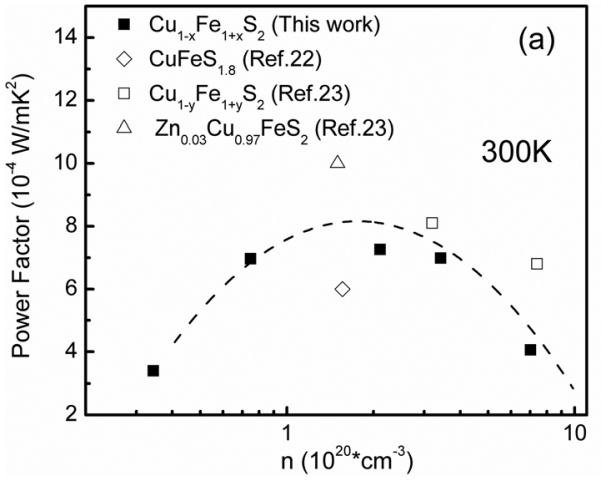

properties. ${ }^{17}$ Figure 9 (b) shows the power factor at $700 \mathrm{~K}$ as a function of tetragonal distortion parameter $(\eta)$ for our $\mathrm{Cu}_{1-\mathrm{x}} \mathrm{Fe}_{1+\mathrm{x}} \mathrm{S}_{2}$ with the estimated trend based on the typically tetrahedral diamond-like compounds. Although $\mathrm{CuFeS}_{2}$ has a $\eta$ value that deviates from unity more than $\mathrm{CuInTe}_{2}$ or $\mathrm{CuGaTe}_{2}$, which leads to low power factors, it is exciting that all our data are below the general trend and the highest power factor is just below the usual curve in tetrahedral diamond-like compounds. This means that our data are fully consistent with theoretical model by Zhang et al. because the estimated curve shown in Fig. 9(b) is the maximum power factor that tetrahedral diamond-like materials can reach.

\section{Thermal conductivity}

Figure 10 shows the low-temperature thermal conductivity $(\kappa)$ and lattice thermal conductivity $\left(\kappa_{\mathrm{L}}\right)$ from 4 to $300 \mathrm{~K}$ for all $\mathrm{Cu}_{1-\mathrm{x}} \mathrm{Fe}_{1+\mathrm{x}} \mathrm{S}_{2}$ samples. The room temperature thermal conductivities of the $\mathrm{Cu}$-site doped $\mathrm{CuFeS}_{2}$ in literatures are plotted for a comparison. ${ }^{23,24}$ The total thermal conductivity consists of carrier thermal conductivity $\left(\kappa_{\mathrm{e}}\right)$ and lattice thermal conductivity $\left(\kappa_{\mathrm{L}}\right)$, written as $\kappa=\kappa_{\mathrm{e}}+\kappa_{\mathrm{L}} \cdot \kappa_{\mathrm{e}}$ is estimated using the Wiedemann-Franz law with a constant Lorentz number $L_{0}=2.0 \times 10^{-8} \mathrm{~V}^{2} / \mathrm{K}^{2} . \kappa_{\mathrm{L}}$ is obtained by subtracting $\kappa_{\mathrm{e}}$ from $\kappa$. Due to the small magnitude of electrical conductivity, the carrier contribution to the total thermal conductivity is very small. In this case, it is reasonable to choose a constant Lorentz number in the calculation of $\kappa_{\mathrm{e}}$. As expected, the $\kappa_{\mathrm{L}}$ values and its temperature dependence are similar to those of total thermal conductivity. This implies that lattice phonon scattering dominating heat conduction in $\mathrm{Cu}_{1-\mathrm{x}} \mathrm{Fe}_{1+\mathrm{x}} \mathrm{S}_{2}$.
When increasing the Fe content, the room temperature $\kappa_{\mathrm{L}}$ is depressed up to $48 \%$, which indicates the non-stoichiometric $\mathrm{Cu} / \mathrm{Fe}$ ratios strongly enhance the phonon scattering. In order to clarify the role of the non-stoichiometric $\mathrm{Cu} / \mathrm{Fe}$ ratios in suppression of the heat transport, the Debye approximation is used to model the temperature dependence of the lattice thermal conductivity for all the samples at low temperature. In the Debye model, lattice thermal conductivity is given by ${ }^{31,32}$

$$
\kappa_{L}=\frac{k_{B}}{2 \pi^{2} v}\left(\frac{k_{B}}{\hbar}\right)^{3} T^{3} \int_{0}^{\theta_{D} / T} \frac{x^{4} e^{x}}{\tau_{c}^{-1}\left(e^{x}-1\right)^{2}} d x
$$

where $x=\hbar \omega / k_{B} T, \omega$ is the phonon frequency, $k_{B}$ is the Boltzmann constant, $\hbar$ is the reduced Planck constant, $\theta_{D}$ is the Debye temperature, $v$ is the velocity of sound, and $\tau_{c}$ is the phonon scattering relaxation time. The overall phonon scattering relaxation rate $\tau_{c}^{-1}$ is written as

$$
\tau_{c}^{-1}=\tau_{B}^{-1}+\tau_{D}^{-1}+\tau_{U}^{-1}=\frac{v}{L}+A \omega^{4}+B \omega^{2} T \mathrm{e}^{-\theta_{D} / 3 T},
$$

where $\tau_{B}, \tau_{D}$, and $\tau_{U}$ are the relaxation times for grain boundary scattering, point defect scattering and phonon-phonon Umklapp scattering, respectively. And $L$ is the grain size, the coefficients $A$ (point defect scattering) and $B$ (Umklapp scattering) are the fitting parameters. In our calculations, the Debye temperature $\left(\theta_{D}\right)$ is $263 \mathrm{~K}$ taken from literature, ${ }^{33}$ and the velocity of sound $(v)$ is $2938 \mathrm{~m} / \mathrm{s}$. This is the averaged value of our $\mathrm{Cu}_{1-\mathrm{x}} \mathrm{Fe}_{1+\mathrm{x}} \mathrm{S}_{2}$ samples excluding sample $\mathrm{Cu}_{0.9} \mathrm{Fe}_{1.1} \mathrm{~S}_{2}$ because of its large deviation from the averaged value. The averaged velocity of sound $\left(v_{\text {ave }}\right)$ for each sample is calculated by the equation $v_{\text {ave }}=\left(1 / 3 v_{l}^{3}+2 / 3 v_{s}^{3}\right)^{1 / 3}$, where $v_{l}$ and $v_{s}$ are longitudinal and shear velocity of sound,
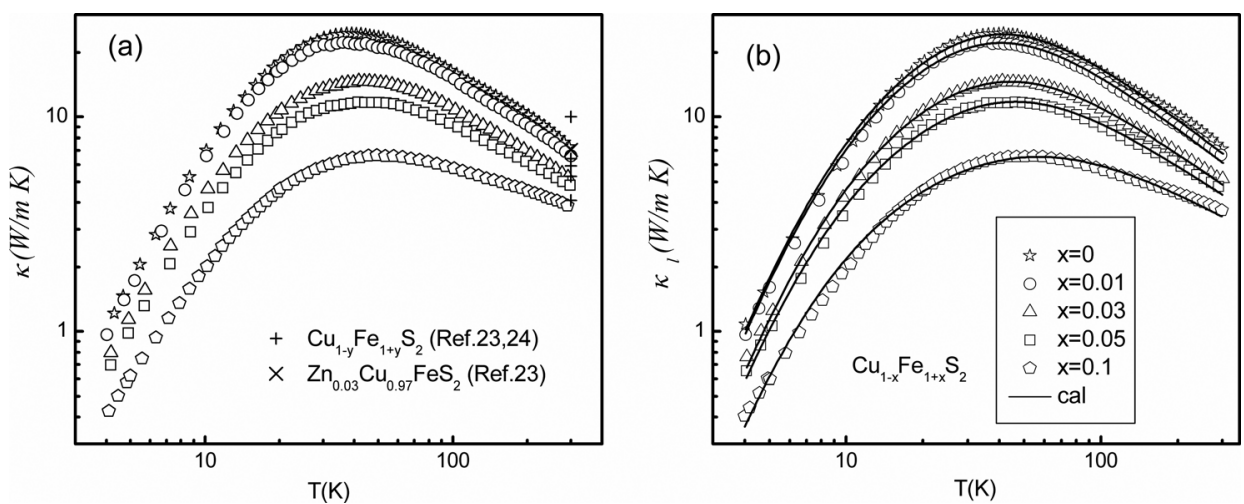

FIG. 10. Low-temperature (a) thermal conductivity $\kappa$ and (b) lattice thermal conductivity $\kappa_{\mathrm{L}}$ from 4 to $300 \mathrm{~K}$ for $\mathrm{Cu}_{1-x} \mathrm{Fe}_{1+x} \mathrm{~S}_{2}$. The data for $\mathrm{Cu}$-site doped $\mathrm{CuFeS}_{2}$ in Refs. 23 and 24 are plotted for a comparison. The solid lines in (b) are calculated curves based on Eqs. (5) and (6).

FIG. 9. (a) Room temperature power concentration $(n)$ for $\mathrm{Cu}_{1-\mathrm{x}} \mathrm{Fe}_{1+\mathrm{x}} \mathrm{S}_{2}$. the figure. ${ }^{22,23}$ (b) Power factors $\left(\alpha^{2} \sigma\right)$ parameter $(\eta)$ for $\mathrm{Cu}_{1-\mathrm{x}} \mathrm{Fe}_{1+\mathrm{x}} \mathrm{S}_{2}$ and ther tetrahedral diamond-like compounds at $700 \mathrm{~K} .{ }^{17}$ The dashed lines

\section{.

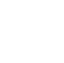


TABLE II. Fitted parameter $L, A, B, \Gamma_{\text {exp }}, \Gamma_{\text {mass }}$, and $\Gamma_{\text {strain }}$ by Eqs. (5)-(8), and longitudinal $\left(v_{l}\right)$, shear $\left(v_{s}\right)$, and averaged $\left(v_{\text {ave }}\right)$ velocity of sound for $\mathrm{Cu}_{1-\mathrm{x}} \mathrm{Fe}_{1+\mathrm{x}} \mathrm{S}_{2}$.

\begin{tabular}{|c|c|c|c|c|c|c|c|c|c|}
\hline $\mathrm{x}$ & $\mathrm{L}(\mu \mathrm{m})$ & A $\left(10^{-43} s^{3}\right)$ & $\mathrm{B}\left(10^{-18} \mathrm{~s} / \mathrm{K}\right)$ & $\Gamma_{\exp }\left(10^{-3}\right)$ & $\Gamma_{\text {mass }}\left(10^{-3}\right)$ & $\Gamma_{\text {strain }}\left(10^{-3}\right)$ & $v_{l}(\mathrm{~m} / \mathrm{s})$ & $v_{s}(\mathrm{~m} / \mathrm{s})$ & $v_{\text {ave }}(\mathrm{m} / \mathrm{s})$ \\
\hline 0 & 3.825 & 11.327 & 3.396 & $\ldots$ & $\ldots$ & $\ldots$ & 3764 & 2056 & 2867 \\
\hline 0.01 & 3.717 & 12.878 & 3.713 & 5.985 & 0.07 & 5.915 & 4227 & 2122 & 3159 \\
\hline 0.03 & 2.519 & 21.29 & 4.195 & 9.895 & 0.206 & 9.689 & 3650 & 1950 & 2765 \\
\hline 0.05 & 2.34 & 29.728 & 4.2 & 13.77 & 0.339 & 13.431 & 3916 & 2065 & 2958 \\
\hline 0.1 & 1.505 & 65.523 & 3.557 & 30.35 & 0.65 & 29.7 & 3256 & 1829 & 2497 \\
\hline
\end{tabular}

respectively. The longitudinal $\left(v_{l}\right)$, shear $\left(v_{s}\right)$, and average ( $v_{\text {ave }}$ ) velocity of sound for all $\mathrm{Cu}_{1-\mathrm{x}} \mathrm{Fe}_{1+\mathrm{x}} \mathrm{S}_{2}$ samples are listed in Table II.

Figure 10(b) plots the fitted curves of lattice thermal conductivity for all $\mathrm{Cu}_{1-x} \mathrm{Fe}_{1+x} \mathrm{~S}_{2}$ samples using Eqs. (5) and (6). The solid lines fit the experimental data very well over the entire temperature range for all five samples, indicating that $\mathrm{Cu}_{1-\mathrm{x}} \mathrm{Fe}_{1+\mathrm{x}} \mathrm{S}_{2}$ is describable in terms of phonon scattering by boundaries, defects, and Umklapp processes. Table II lists the fitted parameters. The grain size $(L)$ varies from about 1.5 to $4 \mu \mathrm{m}$, consistent with the results, ranging from 1 to $20 \mu \mathrm{m}$ observed by SEM. For Umklapp scattering, the prefactor $\mathrm{B}$ is about $4 \times 10^{-18} \mathrm{~s} / \mathrm{K}$ for all the samples and no obvious trend as a function of $x$ is observed. However, the coefficient A for point defect scattering increases notably with increasing doping content as shown in Figure 11. This means the phonon-point defect scattering is strongly enhanced by Fe replacement on the $\mathrm{Cu}$ site, which suppresses the lattice thermal conductivity remarkably.

For exploring the origin of point defect scattering, the coefficient $\mathrm{A}$ is defined as ${ }^{32,34}$

$$
A=\frac{\Omega_{0}}{4 \pi \nu^{3}} \Gamma_{\exp }
$$

where $\Omega_{0}$ is the volume of the primitive cell and $\Gamma_{\exp }$ is an experimental disorder scattering parameter. For $\mathrm{CuFeS}_{2}, \Omega_{0}$ equals to $V / 4$, where $V$ is the volume of unit cell and list in Table I. In general, point defect scattering is a sum of two contributions: mass fluctuation deriving from the mass

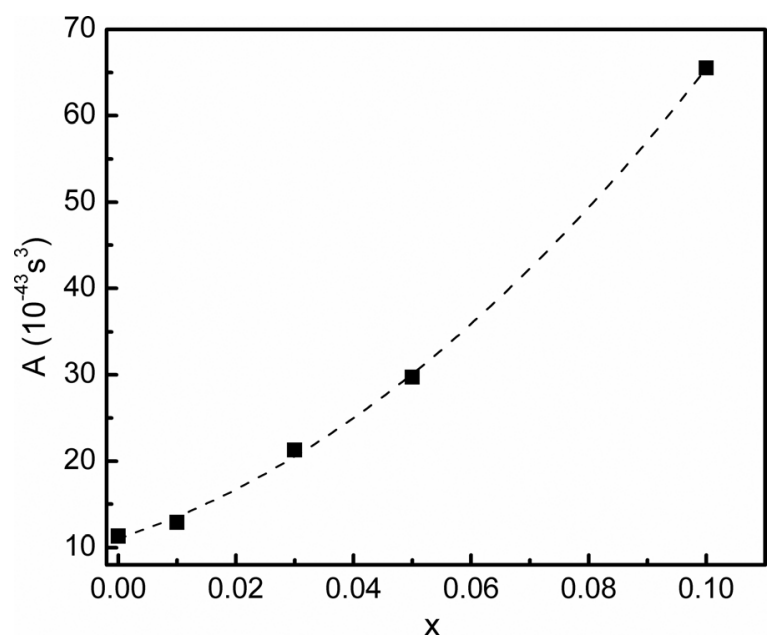

FIG. 11. Coefficient $\mathrm{A}$ as a function of doping content $(x)$. The dashed line is a guide to the eyes. difference between the impurity atom and the matrix atom, and strain field fluctuation due to the difference of atom size and interatomic coupling force. ${ }^{35}$ Thus, $\Gamma_{\exp }$ can be written as $\Gamma_{\exp }=\Gamma_{\text {mass }}+\Gamma_{\text {strain }}$, where $\Gamma_{\text {mass }}$ and $\Gamma_{\text {strain }}$ are scattering parameters concerning mass fluctuation and strain field fluctuation, respectively. For a ternary compound $\mathrm{U}_{u} \mathrm{~V}_{v} \mathrm{~W}_{w}$, the $\Gamma_{\text {mass }}$ is given by ${ }^{10,36}$

$$
\begin{aligned}
& \Gamma_{\text {mass }}\left(U_{u} V_{v} W_{w}\right) \\
& =\frac{u\left(\frac{M_{u}}{M_{m}}\right)^{2} \Gamma(U)+v\left(\frac{M_{v}}{M_{m}}\right)^{2} \Gamma(V)+w\left(\frac{M_{w}}{M_{m}}\right)^{2} \Gamma(W)}{u+v+w},
\end{aligned}
$$

where $M_{m}=\left(u M_{u}+v M_{v}+w M_{w}\right) /(u+v+w)$. For $\mathrm{Cu}_{1-\mathrm{x}}$ $\mathrm{Fe}_{1+\mathrm{x}} \mathrm{S}_{2}, \mathrm{U}=(\mathrm{Cu}, \mathrm{Fe}), \mathrm{V}=\mathrm{Fe}$, and $\mathrm{W}=\mathrm{S}$. For a simple type of impurity atom with a concentration of $\phi$, the scattering parameter is given by $\Gamma=\phi(1-\phi)\left(\Delta M / M_{a v}\right)^{2}$, with $\Delta M=M_{i}-M_{h}$ and $M_{a v}=\phi M_{i}+(1-\phi) M_{h}$, where $M_{i}$ and $M_{h}$ are the masses of the impurity and host atoms, respectively. The $\Gamma_{\text {strain }}$ is obtained by subtracting $\Gamma_{\text {mass }}$ from $\Gamma_{\text {exp }}$. The calculated scattering parameters list in Table II, and $\Gamma_{\text {exp }}$ and $\Gamma_{\text {mass }}$ as a function of $x$ are plotted in Figure 12. As shown, the contributions of mass fluctuation to phonon-point defect scattering are small because the mass difference between $\mathrm{Cu}$ and $\mathrm{Fe}$ is only $10 \%$. Whereas, the values of $\Gamma_{\text {strain }}$ are much larger than the $\Gamma_{\text {mass }}$, which demonstrates that the strain field fluctuation introduced by alloying $\mathrm{Fe}$ on the $\mathrm{Cu}$ sub-lattice is the major contribution to phonon-point

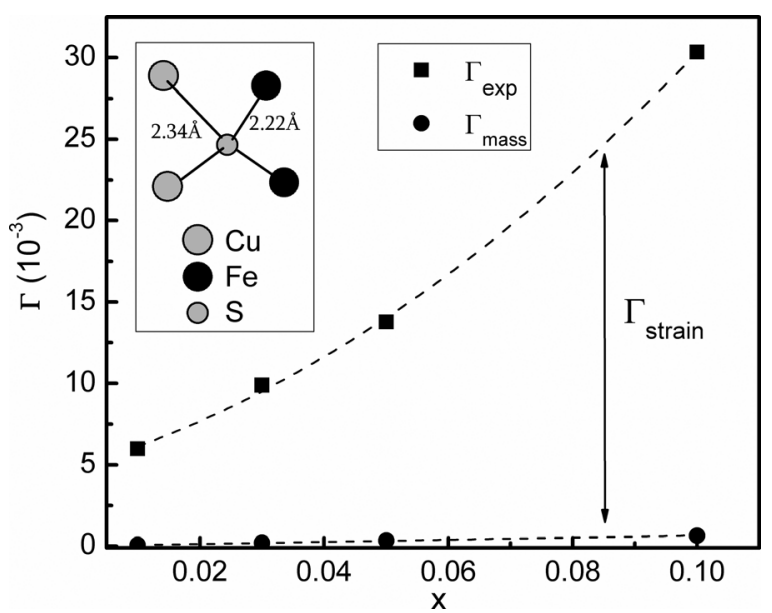

FIG. 12. Parameter $\Gamma_{\exp }$ and $\Gamma_{\text {mass }}$ as a function of doping content $(x)$. The dashed lines are guides to the eyes. The insert figure shows the bonded $\mathrm{Cu}$ $\mathrm{Fe}-\mathrm{S}$ tetrahedron in the lattice of $\mathrm{CuFeS}_{2}$. The bond length of $2.34 \AA$ for $\mathrm{Cu}$ $\mathrm{S}$ bond and $2.22 \mathrm{~A}$ for Fe-S bond are labeled. 
defect scattering, leading to the much lowered lattice thermal conductivity.

In the lattice of $\mathrm{CuFeS}_{2}$, two $\mathrm{Fe}$ atoms and two $\mathrm{Cu}$ atoms bond to a sulfur atom to form a $\mathrm{Cu}-\mathrm{Fe}-\mathrm{S}$ tetrahedron unit as shown in Figure 12. However, the sulfur atom displaces from the center of the bonded tetrahedron, arising that the Fe-S bond is stronger and more anisotropic than the $\mathrm{Cu}-\mathrm{S}$ bond. The calculated bond lengths of $2.34 \AA$ for the $\mathrm{Cu}-\mathrm{S}$ bond and $2.22 \AA$ for the Fe-S bond by Jaffe and Zunger are labeled in Figure $12 .{ }^{37}$ When one $\mathrm{Cu}$ atom is replaced by an extra $\mathrm{Fe}$ atom, the $\mathrm{S}$ atom will further deviate from the center of the tetrahedron toward the final $\mathrm{Cu}$ atom, leading to an extra local distortion. The large differences in the coupling force to the sulfur atom between $\mathrm{Fe}$ and $\mathrm{Cu}$ atoms are expected to give rise to the strong strain fluctuation contributing to phonon scattering. Such a strong strain contribution from $\mathrm{Fe}$ substitution was demonstrated in $\mathrm{Cu}_{2} \mathrm{Zn}_{1-\mathrm{x}} \mathrm{Fe}_{\mathrm{x}} \mathrm{GeSe}_{4}{ }^{38}$

\section{CONCLUSION}

We have investigated the thermoelectric properties of Fe doped chalcopyrite $\mathrm{Cu}_{1-\mathrm{x}} \mathrm{Fe}_{1+\mathrm{x}} \mathrm{S}_{2} \quad(\mathrm{x}=0,0.01,0.03$, $0.05,0.1)$, which were prepared through a melting-annealing-sintering process. All the elements are homogeneously distributed in the samples without obvious impurity phases. With $\mathrm{Fe}$ doping on the $\mathrm{Cu}$ site, the electron concentration is tuned in a wide range from $3.4 \times 10^{19} \mathrm{~cm}^{-3}$ to $7 \times 10^{20} \mathrm{~cm}^{-3}$ at room temperature, indicating $\mathrm{Fe}$ is an effective n-type dopant. The electrical properties follow well the general trend in tetrahedral diamond-like compounds and the optimum carrier concentration is estimated based on our data. We also modeled the much reduced low-temperature thermal conductivity. The disordered ion $\mathrm{Cu} / \mathrm{Fe}$ distributions introduce large strain field fluctuation into the crystal lattice, leading to significantly enhanced phonon-point defect scattering. Optimized power factor and depressed thermal conductivity result in much improved $z T$ values, more than $50 \%$ enhancement at $700 \mathrm{~K}$, due to approach to the optimum carrier concentration and lowered lattice thermal conductivity by the $\mathrm{Fe}$ dopant.

\section{ACKNOWLEDGMENTS}

This work was supported by National Basic Research Program of China (973-program) under Project No. 2013CB632501, and National Natural Science Foundation of China (NSFC) under the Nos. 11234012 and 51121064, and the AFOSR MURI program.
${ }^{1}$ D. M. Rowe, CRC Handbook of Thermoelectrics (CRC Press, Boca Raton, 1995).

${ }^{2}$ L. E. Bell, Science 321, 1457 (2008).

${ }^{3}$ G. J. Snyder and E. S. Toberer, Nat. Mater. 7, 105 (2008).

${ }^{4}$ B. Poudel, Q. Hao, Y. Ma, Y. Lan, A. Minnich, B. Yu, X. Yan, D. Wang, A. Muto, D. Vashaee, X. Chen, J. Liu, M. S. Dresselhaus, G. Chen, and Z. Ren, Science 320, 634 (2008).

${ }^{5}$ K. F. Hsu, S. Loo, F. Guo, W. Chen, J. S. Dyck, C. Uher, T. Hogan, E. K. Polychroniadis, and M. G. Kanatzidis, Science 303, 818 (2004).

${ }^{6}$ K. Biswas, J. He, I. D. Blum, C. Wu, T. P. Hogan, D. N. Seidman, V. P. Dravid, and M. G. Kanatzidis, Nature 489, 414 (2012).

${ }^{7}$ B. C. Sales, D. Mandrus, and R. K. Williams, Science 272, 1325 (1996).

${ }^{8}$ X. Shi, J. Yang, J. R. Salvador, M. Chi, Jung Y. Cho, H. Wang, S. Bai, J. Yang, W. Zhang, and L. Chen, J. Am. Chem. Soc. 133, 7837 (2011).

${ }^{9}$ X. Shi, J. Yang, S. Bai, J. Yang, H. Wang, M. Chi, J. R. Salvador, W. Zhang, L. Chen, and W. Wong-Ng, Adv. Funct. Mater. 20, 755 (2010).

${ }^{10}$ H. Liu, X. Shi, F. Xu, L. Zhang, W. Zhang, L. Chen, Q. Li, C. Uher, T. Day, and G. J. Snyder, Nat. Mater. 11, 422 (2012).

${ }^{11}$ Y. He, T. Day, T. Zhang, H. Liu, X. Shi, L. Chen, and G. J. Snyder, Adv. Mater. 26, 3974 (2014).

${ }^{12}$ X. Lu, D. T. Morelli, Y. Xia, F. Zhou, V. Ozolins, H. Chi, X. Zhou, and C. Uher, Adv. Energy Mater. 3, 342 (2013).

${ }^{13}$ X. Y. Shi, F. Q. Huang, M. L. Liu, and L. D. Chen, Appl. Phys. Lett. 94, 122103 (2009).

${ }^{14}$ X. Shi, L. Xi, J. Fan, W. Zhang, and L. Chen, Chem. Mater 22, 6029 (2010).

${ }^{15}$ R. Liu, L. Xi, H. Liu, X. Shi, W. Zhang, and L. Chen, Chem, Commun. 48, 3818 (2012).

${ }^{16}$ T. Plirdpring, K. Kurosaki, A. Kosuga, T. Day, S. Firdosy, V. Ravi, G. J. Snyder, A. Harnwunggmoung, T. Sugahara, Y. Ohishi, H. Muta, and S. Yamanaka, Adv. Mater. 24, 3622 (2012).

${ }^{17}$ J. Zhang, R. Liu, N. Cheng, Y. Zhang, J. Yang, C. Uher, X. Shi, L. Chen, and W. Zhang, Adv. Mater. 26, 3848 (2014).

${ }^{18}$ I. G. Austin, C. H. L. Goodman, and A. E. Pengelly, Nature 178, 433 (1956).

${ }^{19}$ T. Hamajima, T. Kambara, and K. I. Gondaira, Phys. Rev. B 24, 3349 (1981).

${ }^{20}$ T. Teranishi, J. Phys. Soc. Jpn. 16, 1881 (1961).

${ }^{21}$ B. Donovan and G. Reichenbaum, Br. J. Appl. Phys. 9, 474 (1958).

${ }^{22} \mathrm{~J} . \mathrm{Li}, \mathrm{Q} . \mathrm{Tan}$, and J. Li, J. Alloys Compd. 551, 143 (2013).

${ }^{23}$ N. Tsujii and T. Mori, Appl. Phys. Express 6, 043001 (2013).

${ }^{24}$ N. Tsujii, J. Electron. Mater. 42, 1974 (2013).

${ }^{25}$ H. J. Goldsmid and J. W. Sharp, J. Electron. Mater. 28, 869 (1999).

${ }^{26}$ G. Donnay, L. M. Corliss, J. D. H. Donnay, N. Elliott, and J. M. Hastings, Phys. Rev. 112, 1917 (1958).

${ }^{27}$ N. Cheng, R. H. Liu, S. Q. Bai, X. Shi, and L. D. Chen, J. Appl. Phys. 115, 163705 (2014).

${ }^{28}$ B. M. Askerov, Electron Transport Phenomena in Semiconductors (World Scientific Publishing Co. Pte. Ltd., 1994).

${ }^{29}$ J. Bardeen and W. Shockley, Phys. Rev. 80, 72 (1950).

${ }^{30}$ E. Conwell and V. F. Weisskopf, Phys. Rev. 77, 388 (1950).

${ }^{31}$ J. Callaway, Phys. Rev. 113, 1046 (1959).

${ }^{32}$ J. Callaway and H. C. Baeyer, Phys. Rev. 120, 1149 (1960).

${ }^{33}$ H. N. Ok, K. S. Back, and E. J. Choi, Phys. Rev. B 50, 10327 (1994).

${ }^{34}$ P. G. Klemens, Proc. Phys. Soc. A 68, 1113 (1955).

${ }^{35}$ B. Abeles, Phys. Rev. 131, 1906 (1963).

${ }^{36}$ G. A. Slack, Phys. Rev. 126, 427 (1962).

${ }^{37}$ J. E. Jaffe and A. Zunger, Phys. Rev. B 29, 1882 (1984).

${ }^{38}$ W. G. Zeier, Y. Pei, G. Pomrehn, T. Day, N. Heinz, C. P. Heinrich, G. J. Snyder, and W. Tremel, J. Am. Chem. Soc. 135, 726 (2013). 